\title{
MICTURITION REFLEXES IN MAN
}

\author{
BY \\ P. W. NATHAN
}

From the Neurological Research Unit of the Medical Research Council, National Hospital, Queen Square, London

Barrington (1921), during his investigation of "the reflexes composing reflex micturition" in the cat, found that " active contraction of the bladder" was caused either by distending the bladder " or by slightly moving the catheter in and out in the direction of the urethra". He found that this reflex contraction of the bladder could be evoked by " withdrawing the catheter a fraction of a centimetre and then pushing it back to its original position", or "by running water through the urethra ". Although the rise of bladder pressure produced in this way was not quite as high as that produced by distension, on one occasion the pressure rose to thirteen and a half times its original value. "In many cases", Barrington wrote, " it was quite enough to start reflex micturition, the bladder contents being passed at the side of the catheter".

This stimulation of the urethra causing contraction of the bladder constitutes Barrington's second and seventh reflexes of micturition. The difference between the two reflexes is that in the second the afferent pathway is in the pudic nerves and the efferent pathway in the pelvic nerves, while in the seventh reflex both afferent and efferent pathways are in the pelvic nerves (Barrington, 1941).

Langworthy, Kolb, and Lewis (1940) confirmed the presence of these reflexes in the cat.

From this experimental work it has been concluded that this reflex contraction of the bladder plays an essential part in normal micturition, keeping the bladder contracting as long as urine flows through the urethra. And the presence of residual urine in animals with lesions of the spinal cord has been attributed in part to interruption of these reflexes by the division of the pathways concerned.

During the course of a recent investigation of the effects of lesions of the nervous system on micturition in man, it was noted that the movement of catheters or cystoscopes in and out of the urethra caused no obvious changes in pressure and no contraction of the detrusor. As this was contrary to expectation, in view of Barrington's work, it was decided to subject this observation to more careful and detailed analysis.

The following procedure was adopted in 16 subjects. In all subjects a cystoscope was passed and connected to a water manometer; in the majority on another occasion a catheter was passed into the bladder and connected to the manometer. The bladder was then filled till the subject had a desire to micturate, at which time detrusor contractions occurred spontaneously or could be easily evoked by increasing intra-abdominal pressure or by adding a little more fluid. When this activity had subsided, the catheter or the cystoscope was pushed in and out along the urethra. During catheterization the pressure was recorded, and during cystoscopy the bladder was examined for detrusor activity.

The subjects investigated in these ways consisted of six women and 10 men, who were attending hospital on account of the following disorders: one had a cerebral thrombosis, three had each a single papilloma of the bladder, one had a small nodule of a carcinoma of the bladder, one had previously had a stricture of the urethra, one attended on account of phosphaturia, and the other nine had carcinomata not involving the urinary tract.

In no instance did any of these procedures outlined above cause any rise in vesical pressure or evidence of detrusor contractions.

The observations made on one of these patients, who had previously had a stricture of the urethra, deserve further attention. This subject had a most urgent desire to micturate when the bladder contained a relatively small amount of fluid, and the bladder so often contracted spontaneously that it was difficult to find a period of quiescence of sufficient duration to carry out the stimulation of the urethra. Nevertheless, when, during a period of quiescence, the urethra was stimulated by sliding the cystoscope in and out, no detrusor activity was induced. 
Although Barrington evoked this reflex contraction in the decerebrate cat by moving a smooth foreign body along the urethra, the normal stimulus for this reflex might be thought to be an increase in tension in or a dilatation of the urethra. This stretching of the urethra was reproduced in two normal women and one normal man by means of a Foley catheter. The catheter was passed until the tip was in the bladder; thus the bladder pressure could be recorded. The whole length of the urethra of the female subjects was then distended by blowing up the bag; in the man, that part of the urethra which is common to both sexes was similarly distended. No evidence of bladder contraction was obtained by suddenly dilating the urethra in this manner.

Barrington evoked these two reflexes also by running water through the urethra. This experiment was repeated as nearly as possible on human males with intact nervous systems. Four elderly men were examined, who had had suprapubic cystostomies performed, owing to the obstruction associated with enlargement of the prostate. In none of these cases was the detrusor atonic. This was shown by recording the pressure from the suprapubic tube; when the patient strained to micturate or when the bladder was stretched by filling, the detrusor contracted, raising the pressure to 60 or $110 \mathrm{~cm}$. of water. (The rise in bladder pressure transmitted passively from the rise in intra-abdominal pressure is of the order of $10 \mathrm{~cm}$., and comes on immediately, whereas the rise in pressure due to the reflex evoked by increasing intraabdominal pressure comes on after a latent period, often, indeed, as the intra-abdominal pressure subsides.) In these four subjects the pressure was recorded from the suprapubic tube, while the urethra was stimulated to evoke the reflex. A narrow catheter was introduced into the urethra after the bladder has been distended with fluid; no change in bladder pressure occurred as the catheter was passed along the urethra into the bladder. It was then withdrawn; no change in bladder pressure occurred, as this smooth foreign body was dragged through the sphincters along the urethra. The catheter was then re-introduced into the bladder. Micturition around the catheter was then induced by suddenly adding fluid at a pressure of $40 \mathrm{~cm}$. through the catheter into the already full bladder. After 15 to $20 \mathrm{ml}$. of fluid had been passed around the catheter the bladder ceased to contract, and the spontaneous flow down the urethra stopped. Immediately the flow of fluid stopped, the catheter was again slowly withdrawn down the urethra, and as it was being withdrawn, fluid was made to flow out of it, irrigating the urethra. But the continuous stimulation of the urethra by the stream of fluid flowing down it did not induce the bladder to contract again, and no further micturition took place.

From the investigations reported here, no evidence has been found for the existence in conscious man, with an intact central and peripheral nervous system, of the second and seventh reflexes which Barrington found in the decerebrate cat.

If these reflexes were active in man, cystoscopy could be carried out only with difficulty, for the detrusor would contract whenever the cystoscope was moved along the urethra. Further, one might have expected micturition to take place during catheterization. This rarely occurs in man. Jacobson $(1945,1952)$ who catheterized conscious, unanaesthetized, female dogs, did not find micturition occurring during catheterization of these animals.

The question why the bladder continues, as it usually does, to discharge its contents after its pressure has fallen to a level insufficient to cause contraction, would now seem to remain unanswered, for it has usually been assumed that Barrington's second and seventh reflexes supplied the answer.

\section{Summary}

The reflex contraction of the bladder evoked by moving a smooth foreign body along the urethra or by irrigating the urethra with fluid, as described by Barrington in decerebrate cats, and named by him the second and seventh component reflexes of micturition, was sought for in man. No evidence has been found of its existence.

I should like to thank Mr. Philip Ryan for his help in this investigation, and Mr. Norman Matheson and Mr. Harland Rees for being so kind as to put their cases at my disposal, and Mr. F. J. F. Barrington and Dr. E. A. Carmichael for their interest and critical advice.

\section{REFERENCES}

Barrington, F. J. F. (1921). Brain, 44, 23.

(1941), lbid. 64,239

Jacobson, C. E. (1945). J. Urol., Baltimore, 53, 670.

Jacobson, (1952). Personal communication.

Langworthy O. R., Kolb, L. C., and Lewis, L. G. (1940). Physiology of Micturition. Baltimore. 